\title{
Tensile failure mechanisms in synthetic fibre-reinforced mortar
}

\author{
YOUJIANG WANG \\ School of Textile and Fiber Engineering, Georgia Institute of Technology, Atlanta, \\ Georgia 30332, USA
}

V. C. LI

Department of Civil Engineering, University of Michigan, Ann Arbor, Michigan 48109, USA

S. BACKER

Department of Mechanical Engineering, Massachusetts Institute of Technology, Cambridge, Massachusetts 02139, USA

The ultimate tensile behaviour of fibre-reinforced cementitious composites is closely related to its failure mechanisms which in turn are dependent on reinforcement parameters such as fibre characteristics and the fibre/matrix interface properties. Based on the direct tensile tests of mortar specimens reinforced with various synthetic fibres, this paper attempts to explain such relationships and to indicate directions towards more effective fibre reinforcement.

\section{Introduction}

Concrete, a ubiquitous construction material, has low tensile strength and low fracture toughness which limit its use in many critical applications. Research has indicated that the tensile behaviour of concrete can be effectively upgraded by fibre reinforcement at relatively low fibre volume fractions, typically $0.5 \%$ to $3 \%$. Because of such improvements, fibre-reinforced cementitious composites (FRC) are suitable for many applications.

The tensile behaviour of FRC is a fundamental material property which can be characterized by means of a stress crack opening width $(\sigma-\delta)$ curve [1]. In an experimental study of fibre reinforcement of mortar with various synthetic fibres [2], it was observed that the measured $\sigma-\delta$ curve was strongly influenced by the fibre reinforcement, particularly by the fibre types used, and that, as the differences in $\sigma-\delta$ curves imply, some reinforcements were not as effective as others.

Here, the tensile failure mechanisms in mortar specimens reinforced with various synthetic fibres are studied, based on observations under an optical microscope as well as under a scanning electron microscope (SEM). These mechanisms are related to both the tensile behaviour ( $\sigma-\delta$ curves) of the composites and the reinforcement parameters (fibre type, size and volume fraction). The purpose of this study was to point out directions towards optimization of FRC properties with respect to the reinforcement parameters.

\section{Direct tensile testing of FRC}

Mortar matrix, composed of Type III cement, mortar sand and water (weight ratio $=1: 1: 0.5$ ) was reinfor- ced with various synthetic fibres, including Kevlar 49 (aramid, DuPont Company), Technora (aramid, Teijin Ltd), Spectra 900 (high strength polyethylene, Allied Corporation), and Herculon PP (undrawn polypropylene, Hercules Inc.). Notched specimens, such as shown in Fig. 1, were tested in direct tension using the test fixture illustrated in Fig. 2. A stress-crack opening width $(\sigma-\delta)$ curve was recorded for each test, with the specimen load measured by the machine load cell, and the specimen crack width monitored by a pair of linear variable differential transformers (LVDTs) attached to the specimen. Details on materials, mixing, curing, and testing of FRC specimens can be found elsewhere $[2,3,4]$. Average stress-crack opening width $(\sigma-\delta)$ curves are shown in Fig. 3 for the synthetic FRC tested, along with the information on fibre length $\left(L_{\mathrm{f}}\right)$, diameter $\left(d_{\mathrm{f}}\right)$ and volume fraction $\left(V_{\mathrm{f}}\right)$. Tensile strengths and fracture energies given by the areas under the $\sigma-\delta$ curves are summarized in Table I.
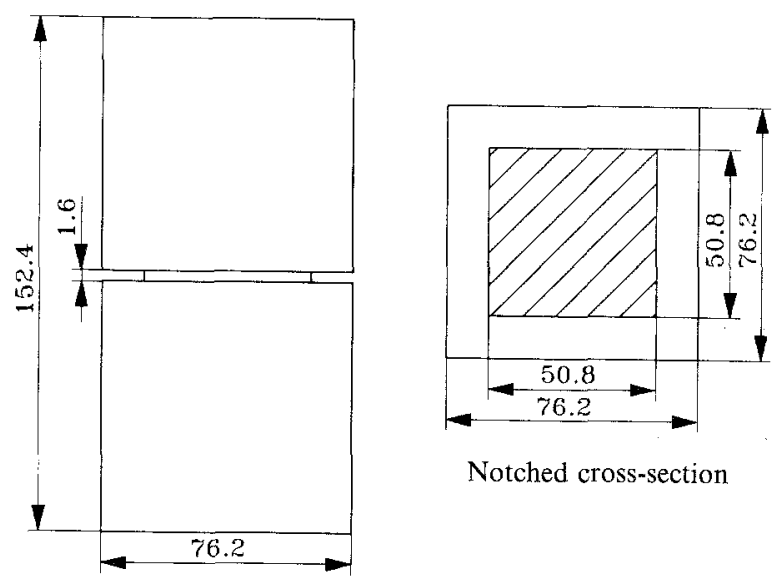

Notched cross-section

Figure 1 Dimensions (mm) of direct tensile test specimens. 


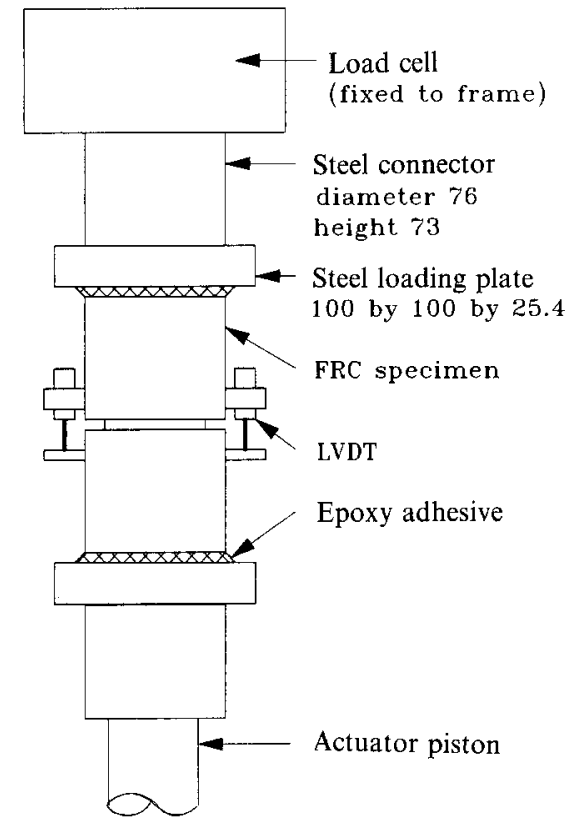

Figure 2 Schematic illustration of the loading fixture for the direct tensile test. Dimensions in $\mathrm{mm}$.
The fracture surfaces of tensile specimens were studied under an optical microscope and under an SEM. For each FRC mix tested in direct tension, a typical sample was chosen for the optical study. For some FRC mixes, a tensile sample was also selected for the SEM study, performed on a Cambridge Instruments Stereoscan microscope. To reduce the time necessary for the vacuum in the SEM chamber to reach the operating level, a $10 \mathrm{~mm}$ thick slice of the tensile specimen containing the fracture surface was cut off with a diamond saw and dried in an oven at $45^{\circ} \mathrm{C}$ for at least $72 \mathrm{~h}$. No conductive coatings were applied to the SEM specimens.

\section{FRC with Spectra $\mathbf{9 0 0}$ fibres}

Spectra 900 fibres, with a finish designed to enhance their dispersion in aqueous media, were observed to distribute uniformly with few fibre bundles formed in mix S1 (containing $1 \% 12.7 \mathrm{~mm}$ fibres). This can be seen in the optical photograph of Fig. 4. In mix S2 with $V_{\mathrm{f}}=2 \%$, however, the fibre distribution was not

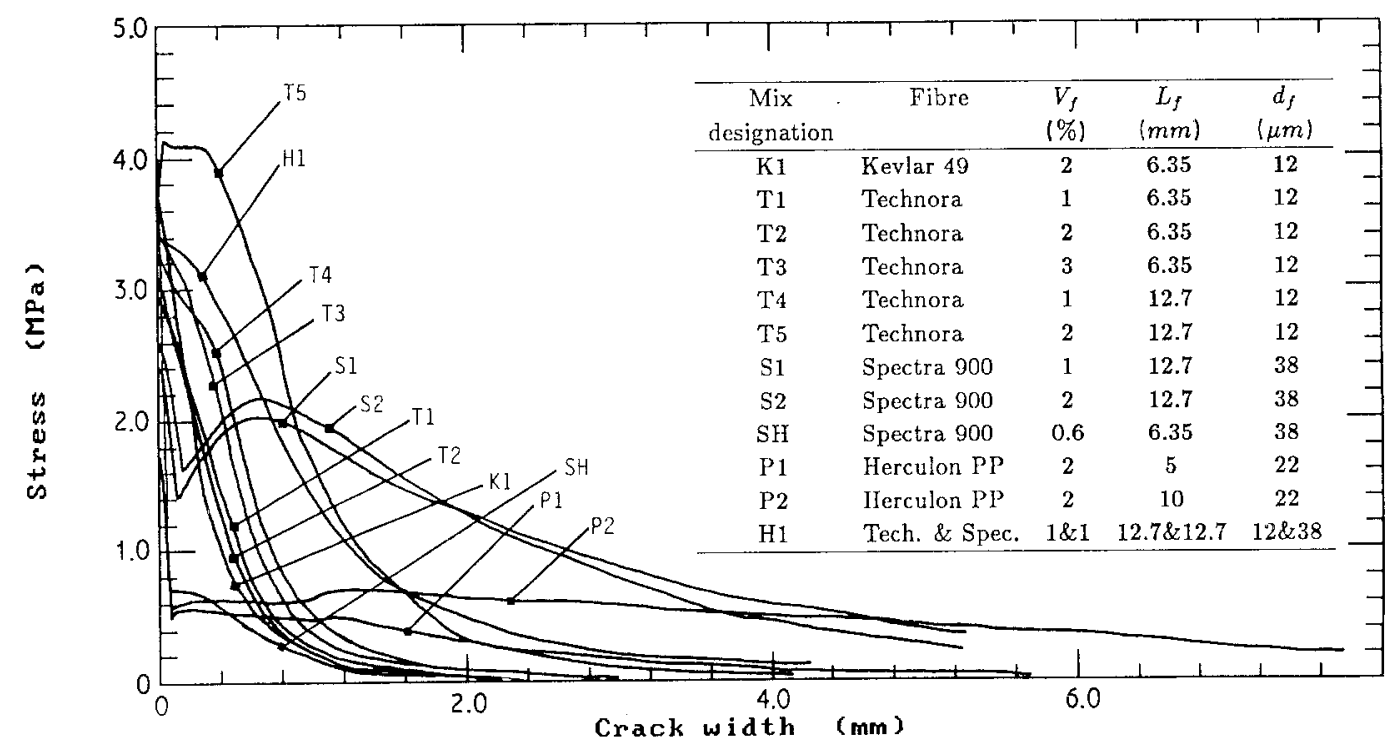

Figure 3 Stress-crack separation curves for FRC.

TABLE I Tensile strength and fracture energy of FRC

\begin{tabular}{|c|c|c|c|c|c|c|c|}
\hline \multirow[t]{2}{*}{ Fibre } & \multirow{2}{*}{$\begin{array}{l}\text { Mix } \\
\text { no. }\end{array}$} & \multirow{2}{*}{$\begin{array}{l}V_{\mathrm{f}} \\
(\%)\end{array}$} & \multirow{2}{*}{$\begin{array}{l}L_{\mathrm{f}} \\
(\mathrm{mm})\end{array}$} & \multicolumn{2}{|c|}{ Tensile strength } & \multicolumn{2}{|c|}{ Fracture energy } \\
\hline & & & & $(\mathrm{MPa})$ & $\mathrm{CV}(\%)$ & $\left(\mathrm{kJ} \mathrm{m}^{-2}\right)$ & $\mathrm{CV}(\%)$ \\
\hline Kevlar 49 & $\mathrm{~K} 1$ & 2 & 6.35 & 3.96 & 11.9 & 1.31 & 13.4 \\
\hline Technora & $\begin{array}{l}\text { T1 } \\
\text { T2 } \\
\text { T3 } \\
\text { T4 } \\
\text { T5 }\end{array}$ & $\begin{array}{l}1 \\
2 \\
3 \\
1 \\
2\end{array}$ & $\begin{array}{c}6.35 \\
6.35 \\
6.35 \\
12.7 \\
12.7\end{array}$ & $\begin{array}{l}3.31 \\
3.11 \\
3.65 \\
3.49 \\
4.17\end{array}$ & $\begin{array}{r}5.0 \\
6.3 \\
12.2 \\
10.9 \\
4.1\end{array}$ & $\begin{array}{l}1.42 \\
1.28 \\
1.87 \\
2.13 \\
4.36\end{array}$ & $\begin{array}{l}17.7 \\
13.4 \\
18.2 \\
30.9 \\
11.0\end{array}$ \\
\hline Spectra 900 & $\begin{array}{l}\text { S1 } \\
\text { S2 } \\
\text { SH }\end{array}$ & $\begin{array}{l}1 \\
2 \\
0.6\end{array}$ & $\begin{array}{c}12.7 \\
12.7 \\
6.35\end{array}$ & $\begin{array}{l}2.39 \\
2.70 \\
4.21\end{array}$ & $\begin{array}{l}8.2 \\
1.9 \\
5.4\end{array}$ & $\begin{array}{l}5.98 \\
5.62 \\
0.39\end{array}$ & $\begin{array}{l}10.3 \\
16.1 \\
10.1\end{array}$ \\
\hline Herculon PP & $\begin{array}{l}\text { P1 } \\
\text { P2 }\end{array}$ & $\begin{array}{l}2 \\
2\end{array}$ & $\begin{array}{r}5 \\
10\end{array}$ & $\begin{array}{l}2.21 \\
2.14\end{array}$ & $\begin{array}{r}9.5 \\
13.3\end{array}$ & $\begin{array}{l}1.44 \\
4.58\end{array}$ & $\begin{array}{r}8.8 \\
12.4\end{array}$ \\
\hline $\left.\begin{array}{l}\text { Technora } \\
\text { and } \\
\text { Spectra } 900\end{array}\right\}$ & H1 & 1 & 12.7 & 3.40 & 2.7 & 3.80 & 9.0 \\
\hline
\end{tabular}



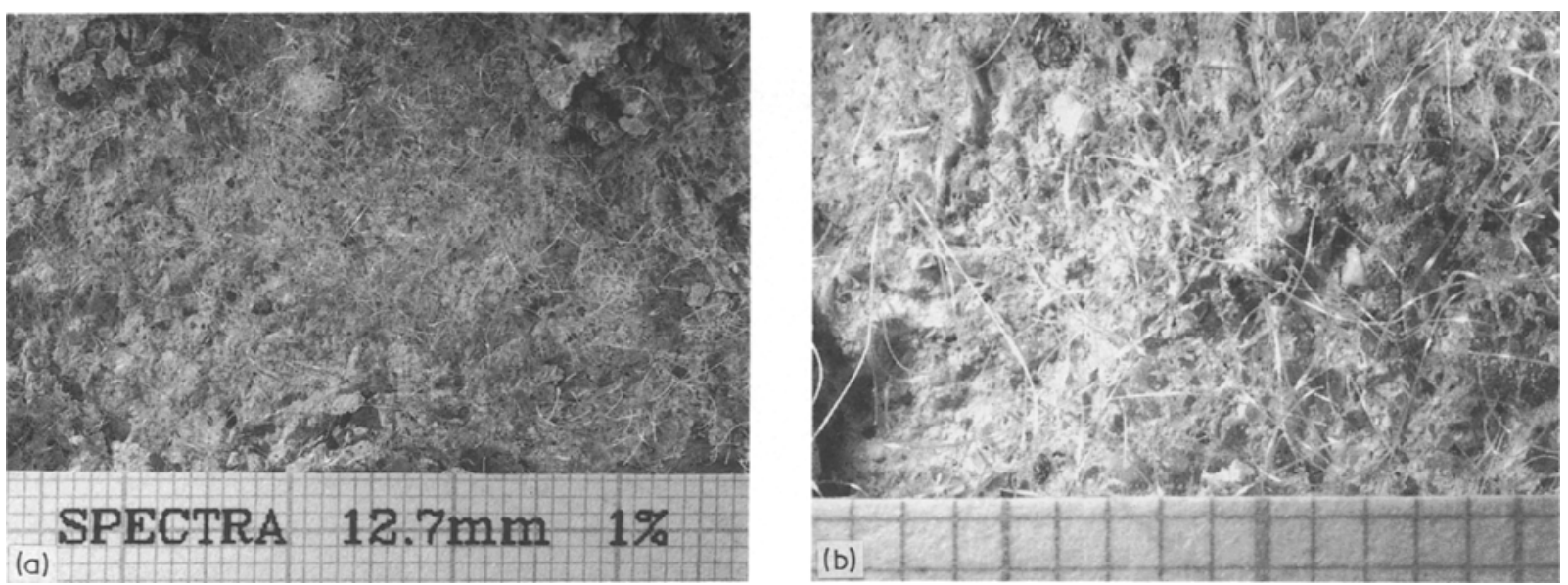

Figure 4 Photographs of fracture surface of mix S1 tested in direct tension. Spacing of grids in photographs is $1 \mathrm{~mm} / \mathrm{grid}$.

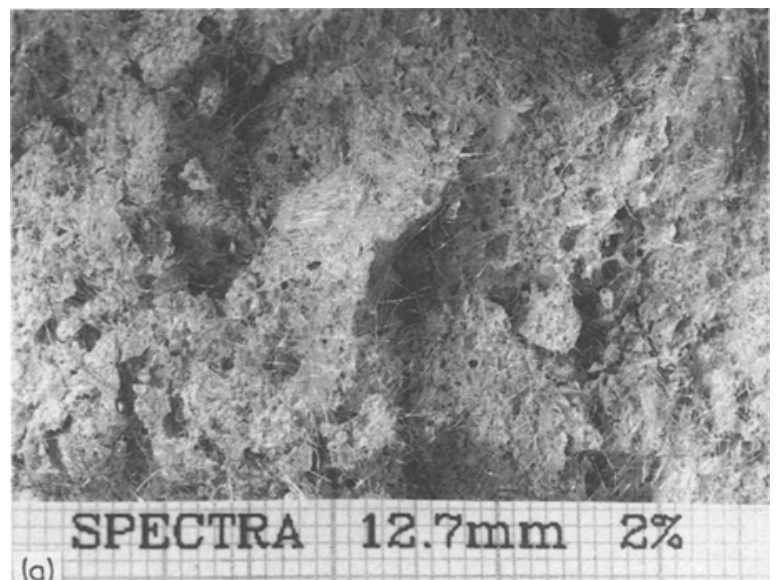

(a)

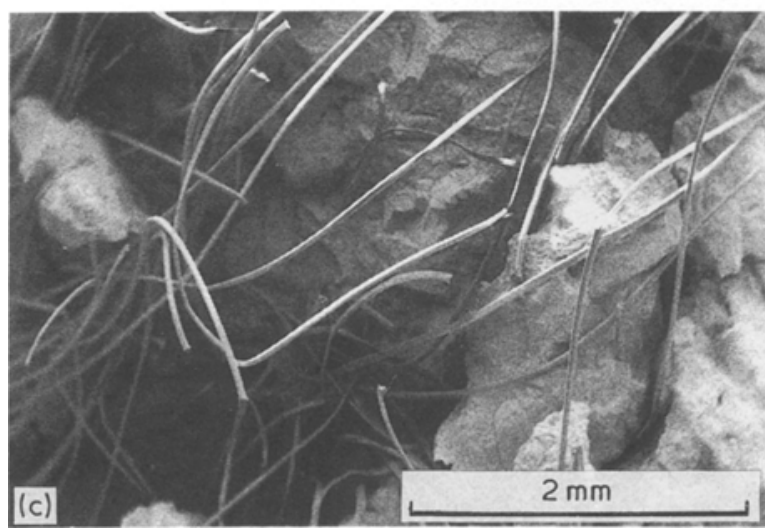

uniform, as indicated by the photographs in Fig. 5. Bundles consisting of parallel fibres (Fig. 5b) and clumps of fibres (Fig. 5c) can be seen.

For FRC with randomly distributed fibres, the number of fibres, $N$, across a cross-sectional area, $A_{\mathrm{c}}$, is given by [5]

$$
N=\frac{V_{\mathrm{f}} A_{\mathrm{c}}}{2 A_{\mathrm{f}}}=\frac{2 V_{\mathrm{f}} A_{\mathrm{c}}}{\pi d_{\mathrm{f}}^{2}}
$$

where $A_{\mathrm{f}}$ is the fibre cross-sectional area and $d_{\mathrm{f}}$ is the fibre diameter. For FRC mixes $\mathrm{S} 1$ and $\mathrm{S} 2\left(d_{\mathrm{f}}\right.$ $=0.038 \mathrm{~mm})$, the theoretical numbers of fibres per unit area $\left(N / A_{c}\right)$ are 4.4 and 8.8 fibres $\mathrm{mm}^{-2}$, respectively. Clearly, as the fibre volume fraction increases,

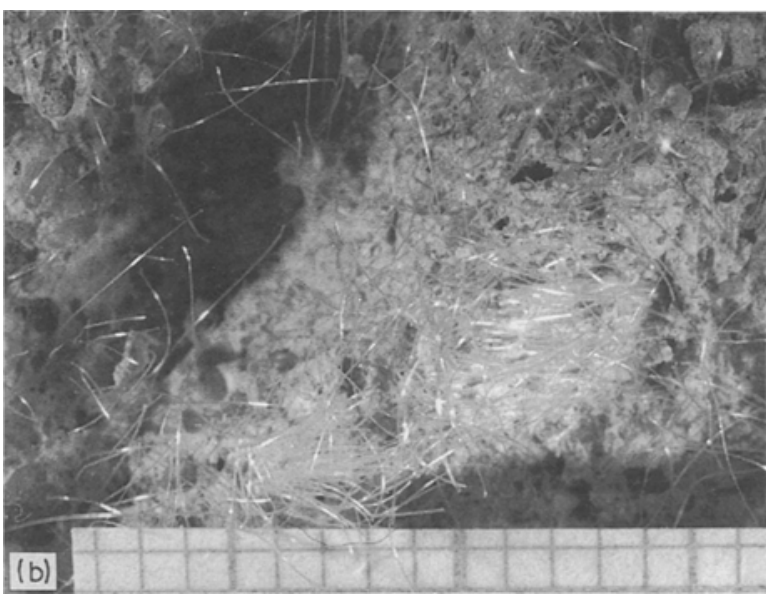

Figure 5 Photographs of fracture surface of mix S2 tested in direct tension. (a, b) Optical micrograph, (c) scanning electron micrograph. Spacing of grids in optical photographs is $1 \mathrm{~mm} /$ grid.

interference between fibres increases and as a result, uniformity of fibre distribution deteriorates. The formation of fibre bundles reduces the effectiveness of fibre reinforcement. The $\sigma-\delta$ curves of mixes $S 1$ and S2 obtained in direct tensile tests did not show a significant difference despite the two-fold increase in fibre volume fraction (Fig. 3). The presence of fibre bundles and clumps in mix S2 $\left(V_{\mathrm{f}}=2 \%\right)$ is certainly one of the reasons for this. Thus it appears from these observations that the maximum fibre volume fraction which can be included in this matrix without causing severe fibre bundling and clumping is around or slightly more than $1 \%$ for these Spectra fibre reinforcements.

In mixes $\mathrm{S} 1$ and $\mathrm{S} 2$, all the fibres initially bridging the crack surface were pulled out, and no ruptured fibres could be identified under the SEM (see Fig. 5c). The critical length of fibre pull-out, $L_{\mathrm{c}}$, defined as the maximum fibre embedded length for the fibre to be pulled out without rupture, is given as follows for the Spectra 900 fibres

$$
L_{\mathrm{c}}=\frac{d_{\mathrm{f}} \sigma_{\mathrm{f}}^{\mathrm{u}}}{4 \tau}=\frac{0.038 \times 2600}{4 \times 1.02}=24.2 \mathrm{~mm}
$$

where $\sigma_{\mathrm{f}}^{\mathrm{u}}=2600 \mathrm{MPa}$ is the fibre breaking strength 
and $\tau=1.02 \mathrm{MPa}$ is the measured fibre/matrix bond strength [6]. Because this $L_{\mathrm{c}}$ far exceeds the fibre length used in mixes S1 and S2 $\left(L_{\mathrm{f}}=12.7 \mathrm{~mm}\right)$, the observation of no fibre rupture is as expected. The short length of $L_{\mathrm{f}}$ relative to $L_{\mathrm{c}}$ indicates that the fibre strength has not been effectively used in the FRC. Further improvement in composite properties could be achieved with even lower fibre volume fraction if the fibre/matrix bond strength, $\tau$, were increased. The bond strength can be increased by, for example, modification of the surface characteristics, plasma treatment, mechanical crimping or crushing.

Matrix spalling due to fibre pull-out at angles was observed in the direct tensile test of mixes S1 and S2. Large numbers of mortar segments were separated from the specimen during testing and some such remaining pieces can be seen in the scanning electron micrograph of Fig. 6. The dimension of the spalled pieces shown in the photograph is typically 1 to $2 \mathrm{~mm}$, which is close to the size of the sand component of the matrix. This phenomenon of matrix spalling has been observed in tests of single-fibre pull-out at different angles [6]. In that study it was found that the tension in the fibre was suddenly released when the matrix wedge spalled off. Correspondingly, in the direct tensile tests, the stress shortly after matrix cracking also exhibited a sudden drop and a subsequent rise as shown in Fig. 3.

The fracture surface of mix $\mathrm{SH}$, a high strength concrete reinforced with $0.6 \% 6.35 \mathrm{~mm}$ Spectra 900 fibres, is shown in Fig. 7. In contrast to mixes S1 and $\mathbf{S} 2$, no noticeable matrix spalling was observed in the test of mix SH. Increased matrix strength certainly was one of the major reasons, and shorter fibre length and lower fibre volume fraction used in this mix might also have played a role.

In structural applications, both the total fracture energy and the energy absorption when the crack width is within the limit of serviceability requirement are important. Obviously, the load drops after matrix cracking for FRC mixes S1 and S2 are not desirable. As demonstrated by tests of fibre pull-out at an angle from a high-strength matrix and by the preliminary study of fibre-reinforced high-strength concrete (mix $\mathrm{SH}$ ), matrix spalling can be significantly reduced. In-

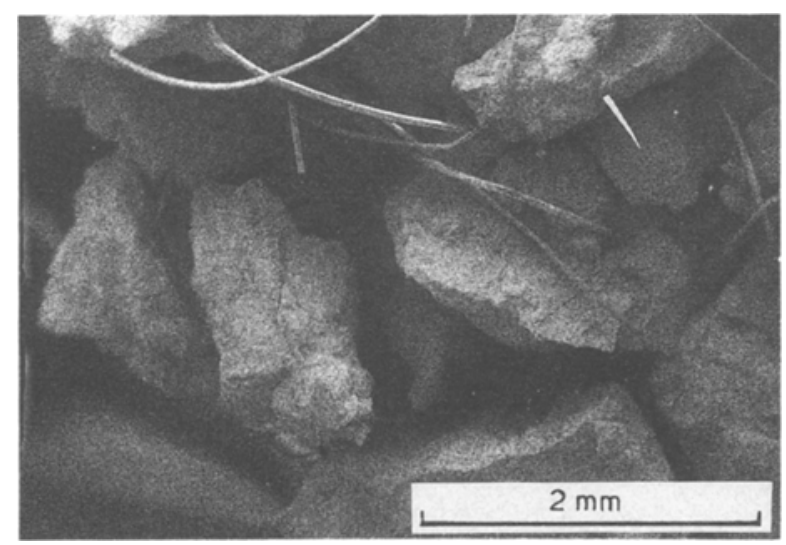

Figure 6 Scanning electron micrograph of fracture surface of mix S2 tested in direct tension.

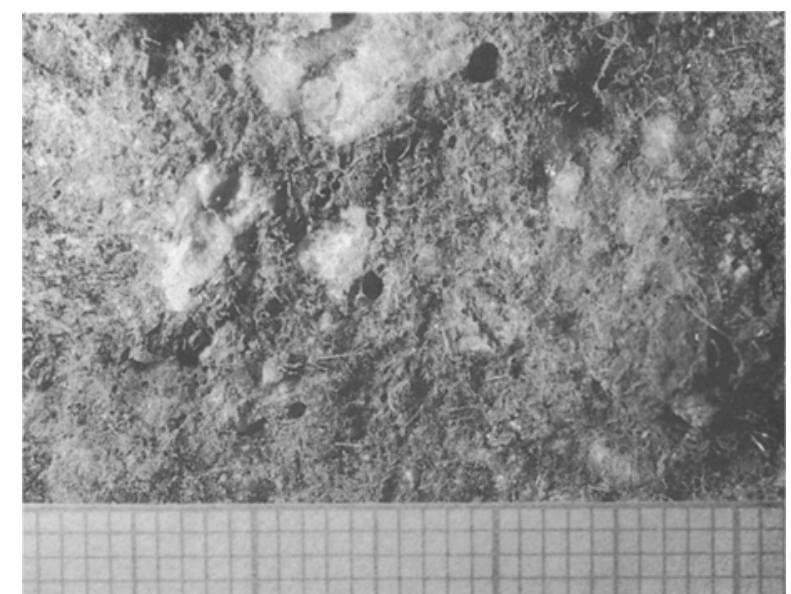

Figure 7 Photographs of fracture surface of mix SH tested in direct tension. Spacing of grids in photograph is $1 \mathrm{~mm} / \mathrm{grid}$.

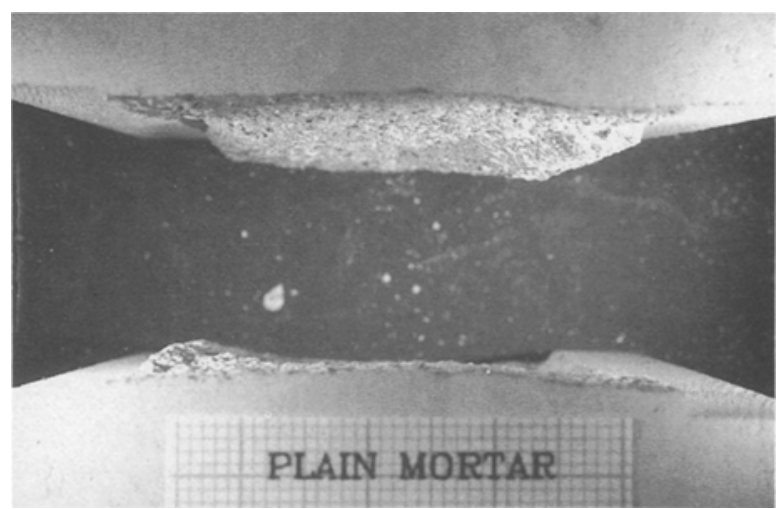

Figure 8 Photograph of fracture surface profile of a mortar specimen failed in direct tension. Spacing of grids in photograph is $1 \mathrm{~mm} /$ grid.

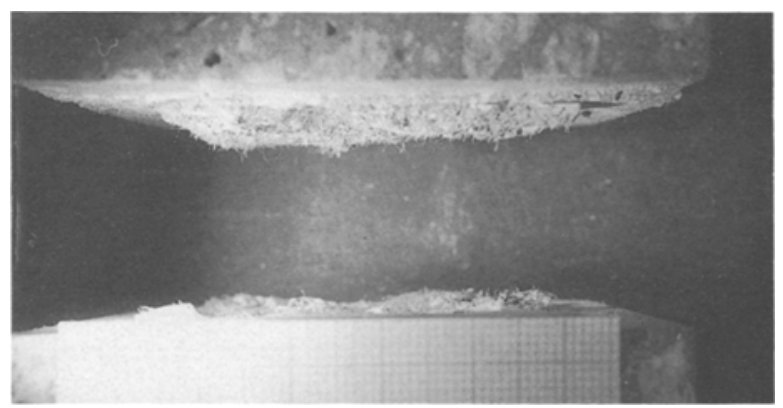

Figure 9 Photograph of fracture surface profile of mix SH tested in direct tension. Spacing of grids in photograph is $1 \mathrm{~mm} /$ grid.

creasing the matrix strength using high-strength concrete technology is clearly one of the key directions towards high-performance cost-effective FRC.

The fracture surface of the plain mortar specimen tested in direct tension is, as expected, quite flat, as shown in Fig. 8. Similar fracture surface profiles can also be seen in specimens of mix SH, shown in Fig. 9, which failed by crack propagation across a planar surface, cutting through the coarse aggregates, and followed by fibre pull-out. Because of the high strength of the matrix, short fibre length and low fibre 

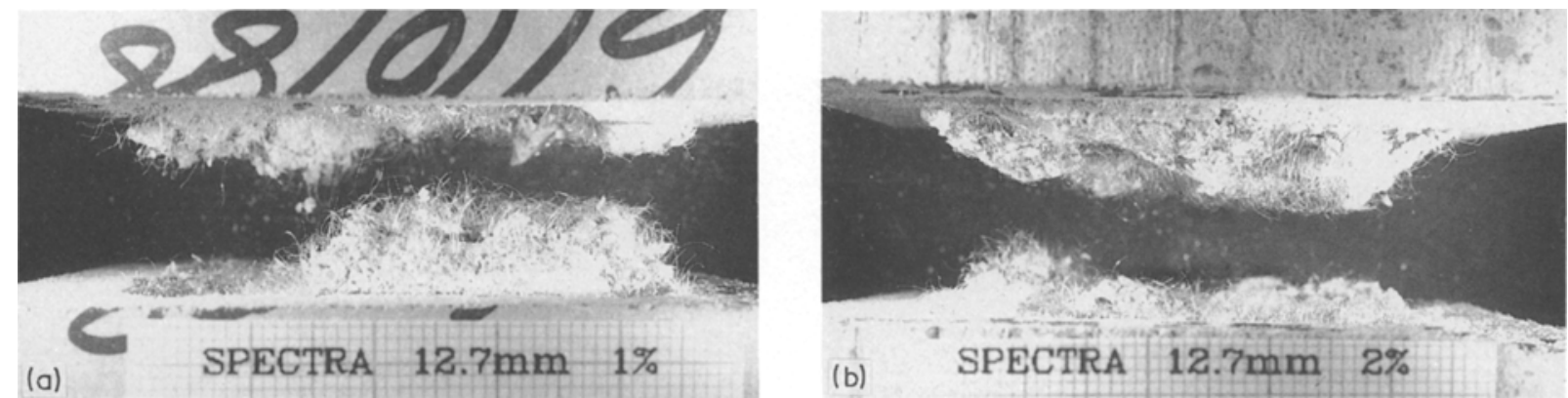

Figure 10 Photograph of fracture surface profile of specimens tested in direct tension. (a) Mix S1, (b) mix S2. Spacing of grids in photograph is $1 \mathrm{~mm} /$ grid.

volume fraction used in this mix, the crack propagation was essentially not influenced by the presence of fibres.

The fracture surface profiles of tensile specimens of mixes $\mathrm{S} 1$ and $\mathrm{S} 2$ were affected by the reinforcing fibres, as illustrated in Fig. 10. The crack surfaces, covered with fibres, were relatively rough. Sometimes, multiple crackings of the matrix were observed.

\section{FRC with aramid fibres}

Bundles of fibres were the dominant form of fibre distribution in all the aramid FRC tested (mixes K1, $\mathrm{T} 1$ to T5), as shown by some typical scanning electron micrographs in Fig. 11. The vast majority of the reinforcing fibres appeared in bundles or clumps in the matrix although some isolated fibres can also be seen (Fig. 12).

The main failure mechanisms in aramid FRC were
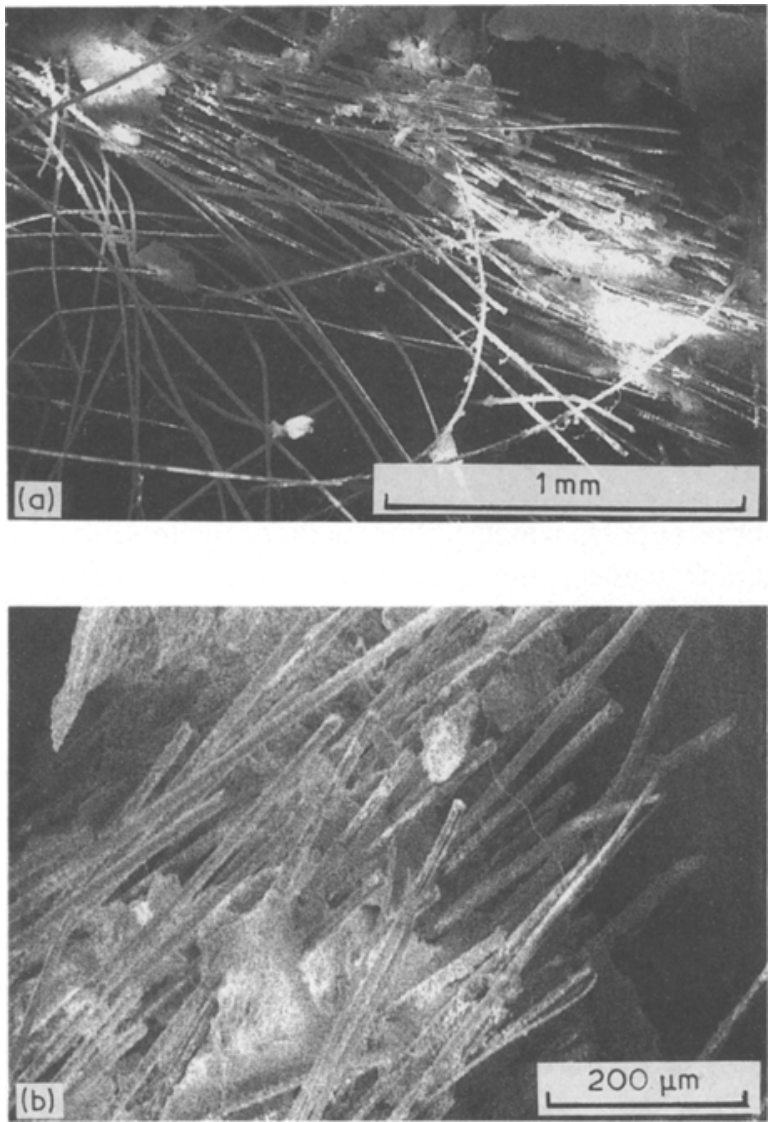

crack deflection around fibre bundles, bundle splitting and bundle shearing. Fibre bundles infiltrated by the cement slurry may act as rigid rods in the matrix. When the matrix crack encounters a bundle lying in a direction close to that of the applied load, the crack is likely to deflect around the bundle, leaving a "cone" of fibre bundle surrounded by cement on the crack surface, like those shown in Fig. 13. A plausible reason why a cone is pulled out rather than the fibre bundle itself is that the fibre/matrix bond strength for aramid fibres is very high ( $\tau=4.5 \mathrm{MPa}$ from experiment [6], about four times that for Spectra 900 fibres), and before the shear stress at the interface has reached the level of the bond strength, the matrix has failed in tension in the directions of maximum tensile stress, as schematically illustrated in Fig. 14. Because of this cone-shaped separation geometry, direct pull-out of fibre bundles does not provide significant postcracking resistance.

When the crack confronts fibre bundles lying nearly perpendicular to the loading direction, the crack may turn and propagate through the bundle in the bundle longitudinal direction. As the crack opens further, the bundles are split (Fig. 11) or peeled off from the matrix (Fig. 15). In some cases, bundle splitting may also be associated with fibre splitting (fibrillation), as shown in Fig. 16.

Figure 11 Scanning electron micrographs of fracture surfaces of aramid FRC tested in direct tension. (a) mix T1, Technora $6.35 \mathrm{~mm}$

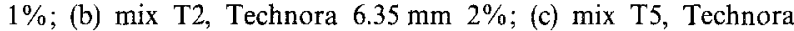
$12.7 \mathrm{~mm} 2 \%$.

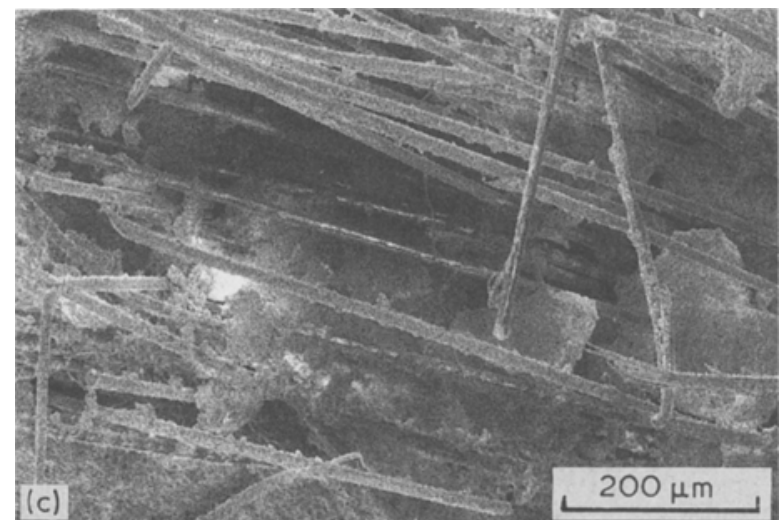




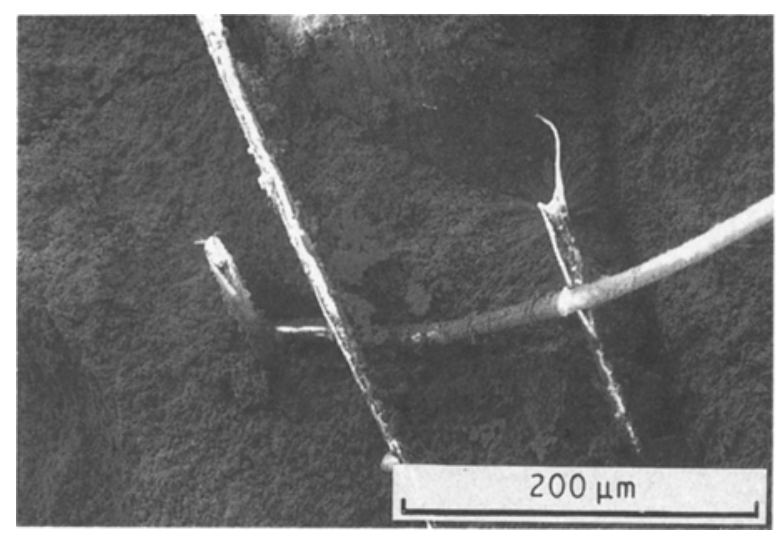

Figure 12 Scanning electron micrographs of fracture surfaces of mix T1 tested in direct tension showing isolated fibres.

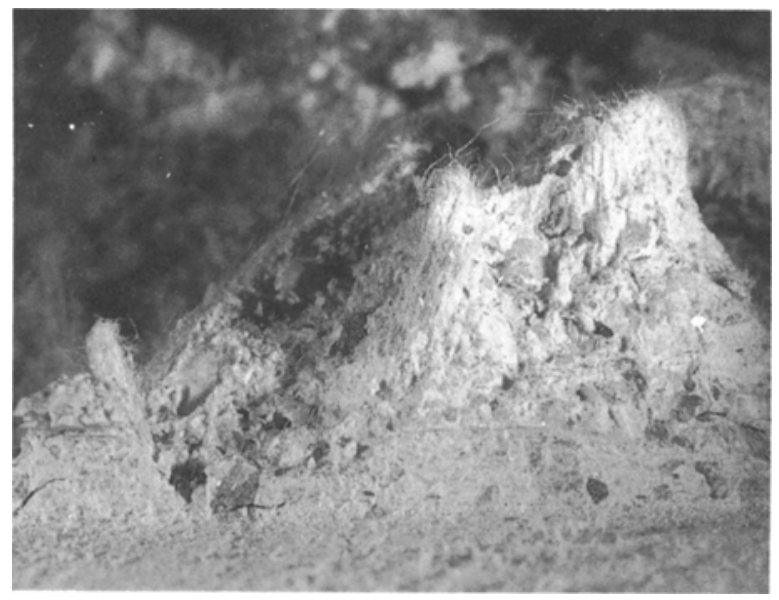

Figure 13 Photograph of cones on the fracture surface formed by fibre bundles (mix T5).

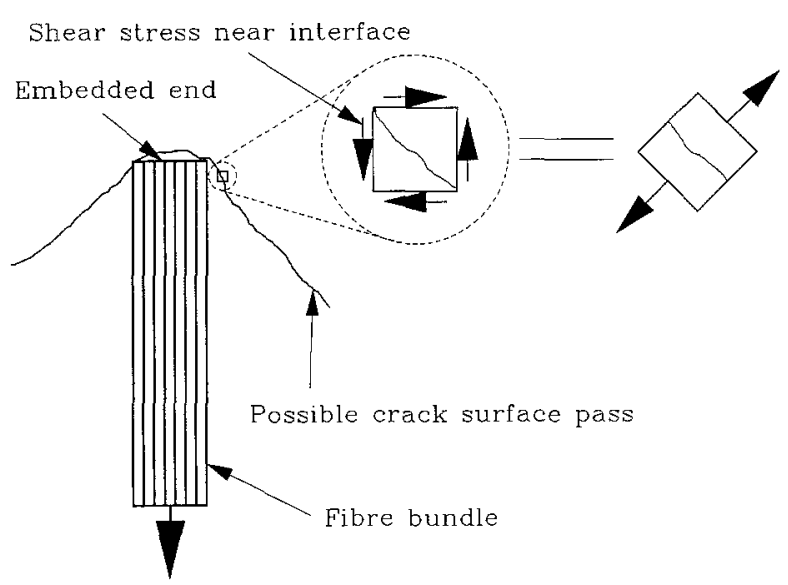

Figure 14 Illustration of stress states in the matrix near the fibre/ matrix interface.

Because the crack growth along a fibre bundle may not coincide with the bundle axis, it is possible for some fibre bundles lying nearly perpendicular to the loading direction to have one end fixed to one crack surface and the other end to the opposite surface, particularly in aramid FRC with long-length fibres. Shearing of these fibre bundles as the crack opens provides relatively high resistance.

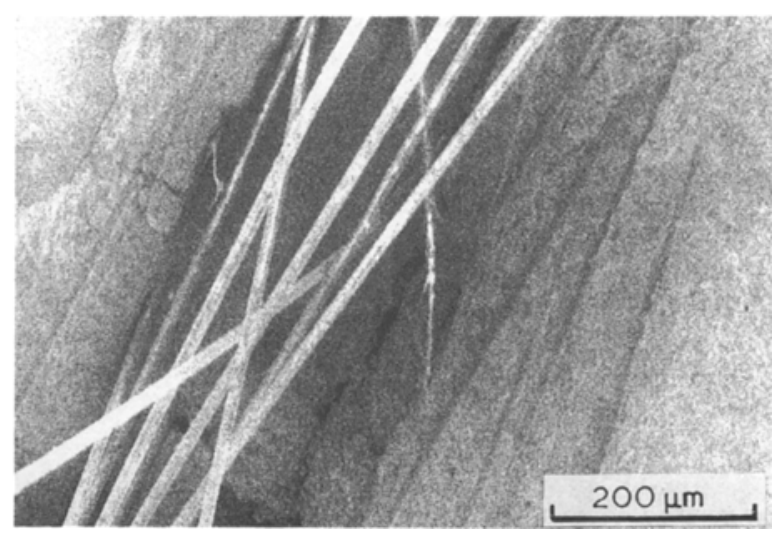

Figure 15 Scanning electron micrograph of mix $\mathrm{T} 2$ showing fibres being peeled off the matrix.

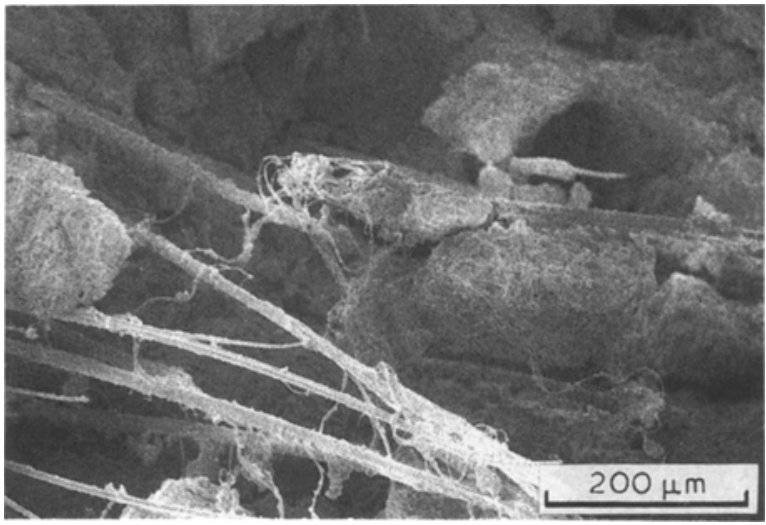

Figure 16 Scanning electron micrograph of mix T5 showing fibre splitting.

Because of the high strength of the fibre/matrix bond, individual fibre pull-out is basically absent in aramid FRC. Fibre tensile rupture, being observed in relatively few isolated fibres, does not play a major role in influencing the tensile behaviour.

The fracture surface profiles of tensile specimens of these FRC are shown in Fig. 17. It can be seen that these fracture surfaces are very irregular, particularly for mixes T4 and T5 with long fibres.

These observations of failure mechanisms are consistent with the direct test results for aramid FRC. Because the crack always tries to propagate through fibre bundles which possess a slight inclination to the crack plane rather than taking a planar path at a random location, it follows that the number of fibre bundles encountered by the crack will not be proportional to the number of fibres across a given plane. Consequently, the $\sigma-\delta$ curves for aramid FRC (Fig. 3) may show very weak dependence on the fibre volume fraction.

Because the cracks in aramid specimens could not directly propagate through the notch plane but instead were forced to deflect out of plane, the strengths of aramid FRC in the direct tensile test were consistently higher than those for FRC with Spectra 900 and Herculon PP fibres.

For FRC mixes with short aramid fibres (mixes K1, 

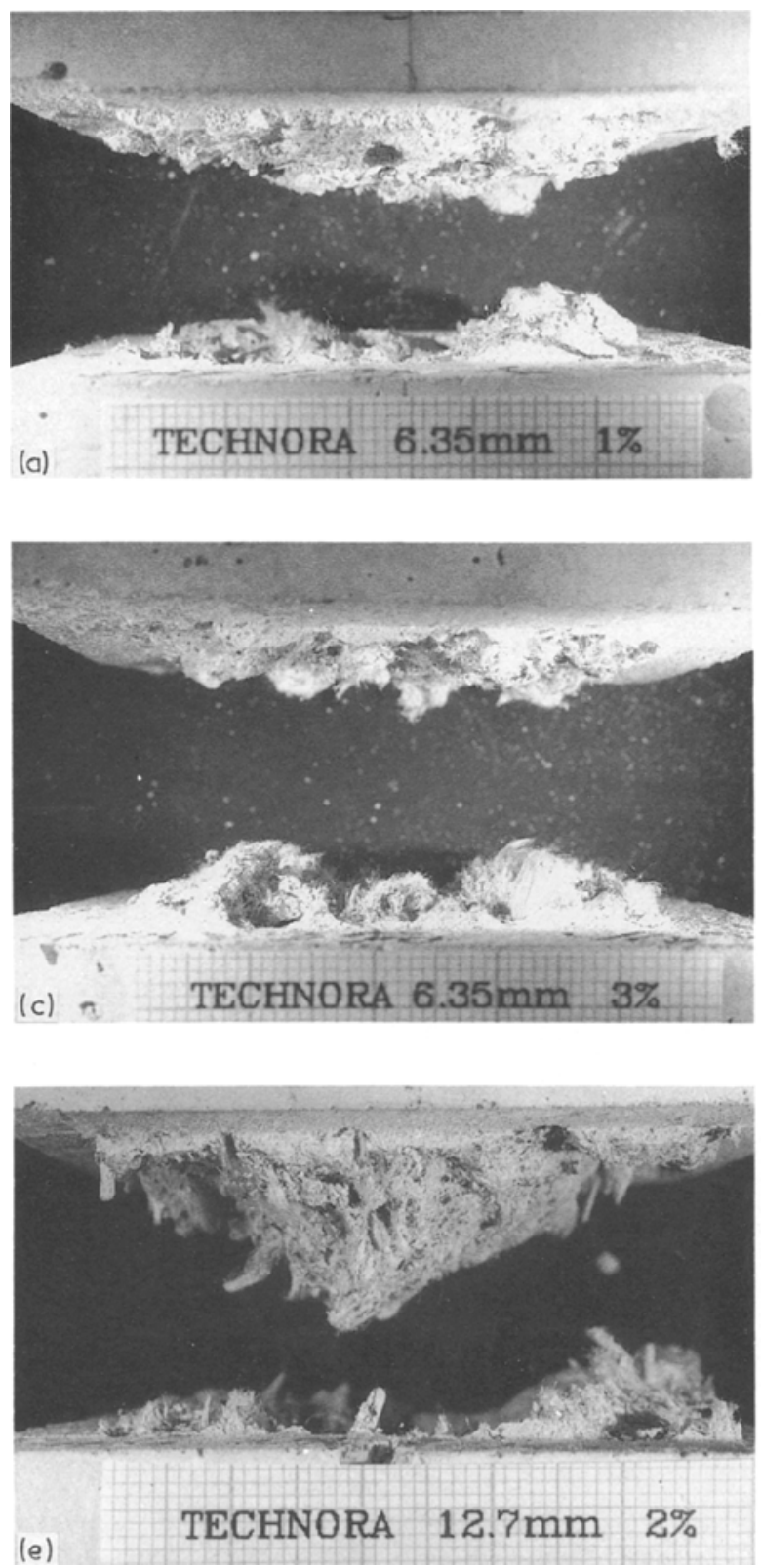
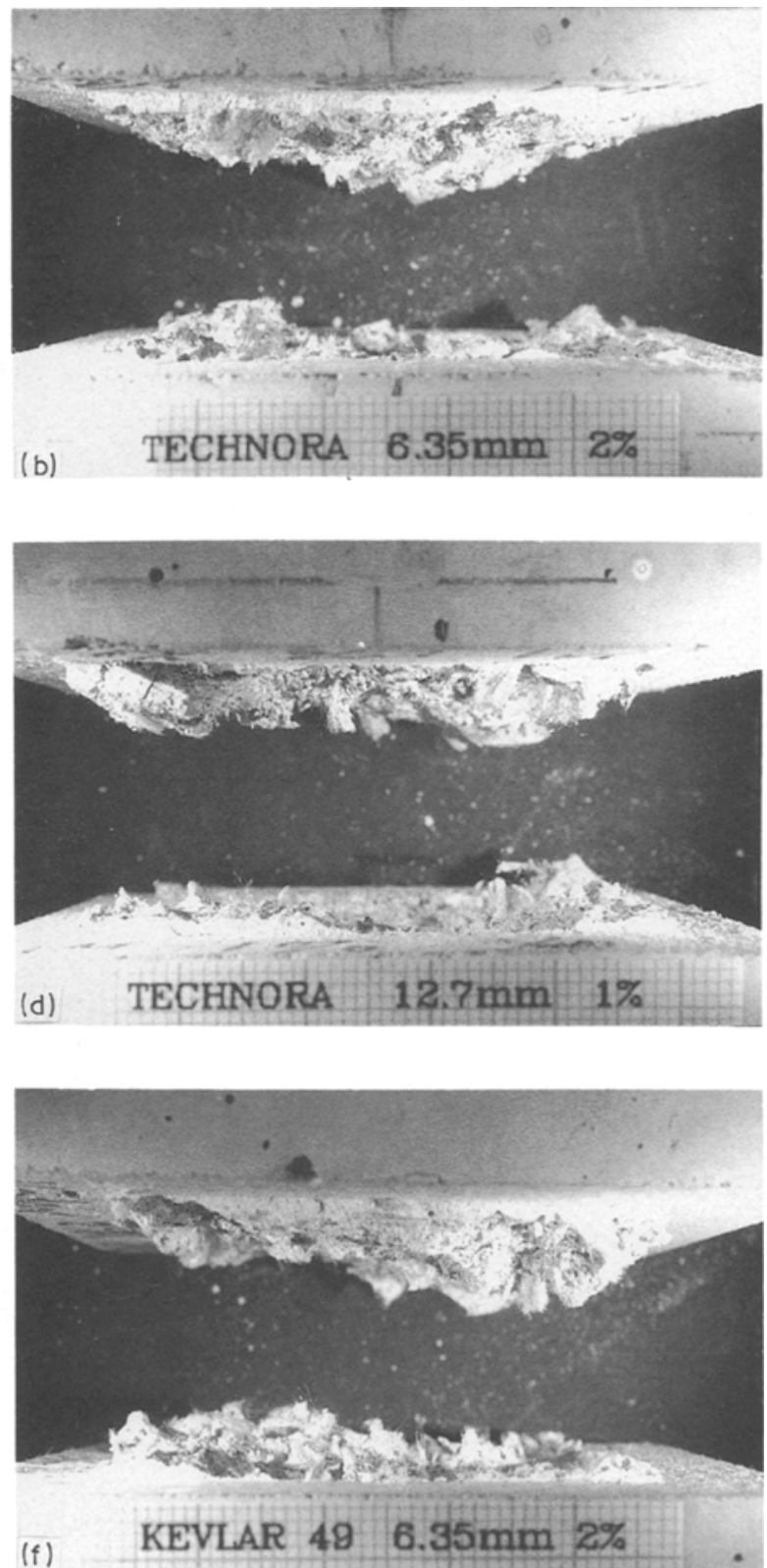

Figure 17 Photographs of fracture surface profiles of aramid FRC specimens tested in direct tension. (a) Mix T1, (b) mix T2, (c) mix T3, (d) mix T4, (e) mix T5, (f) mix K1. Spacing of grids in photograph is $1 \mathrm{~mm} /$ grid.

T1 to T3, all with $L_{\mathrm{f}}=6.35 \mathrm{~mm}$ ), the post-cracking resistance was due primarily to bundle splitting, therefore the stresses in these curves dropped sharply after cracking. For mixes with longer fibres (mixes $\mathrm{T} 4$ and T5, both with $L_{\mathrm{f}}=12.7 \mathrm{~mm}$ ), bundle shearing also became important, and the load drops occurred when the crack openings were wider. Because of the lack of fibre pull-out in aramid FRC, the crack width at which the load dropped off was much smaller than half the fibre length. As a result, the fracture energies of these aramid FRC, except for mix T5, were relatively low in comparison with Spectra FRC showing fibre pull-out behaviour.

The major reason for aramid fibres in FRC to be in bundle form rather than being separated is that the surface finishes available do not promote good fibre dispersion in aqueous solutions. In order to use aramid fibres effectively in FRC, a suitable finish should be provided to ensure even fibre dispersion in cement slurry and to reduce the fibre/matrix bond strength to a desirable level.

\section{Technora/Spectra hybrid FRC}

The fracture surface of mix H1, a hybrid FRC containing $1 \% 12.7 \mathrm{~mm}$ Technora and $1 \% 12.7 \mathrm{~mm}$ Spectra 900 fibres, tested in tension is shown in Fig. 18. It was observed in the specimens that the majority of Technora fibres were in fibre bundles and that the Spectra 900 fibres were partially in separated form and partially in bundles. The fracture surface profile of mix H1, shown in Fig. 19, is very similar to those of aramid FRC. On the fracture surface, Spectra 900 fibres pulled out from the matrix can also be seen.

The failure mechanisms for this hybrid FRC are the combination of those of aramid FRC and those of Spectra FRC. The $\sigma-\delta$ curve of mix H1 (Fig. 3 ) is very close to the average, rather than the sum, of those of 


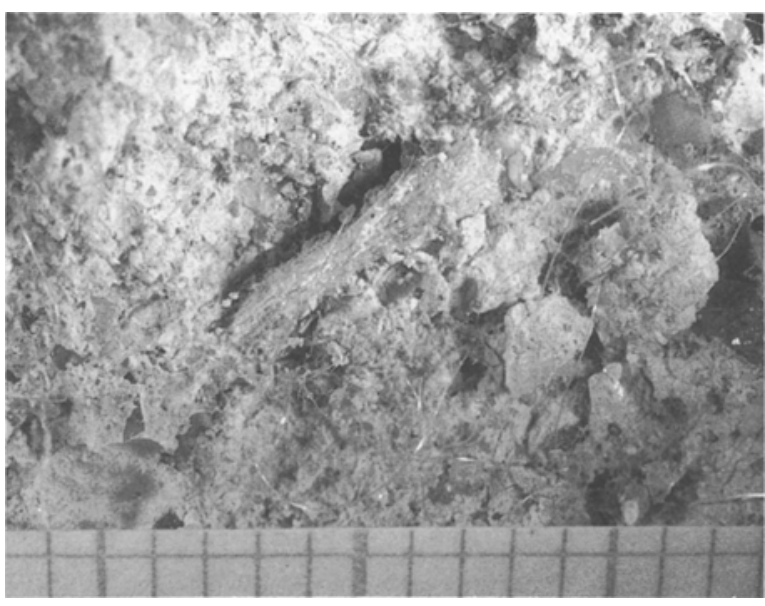

Figure 18 Photographs of fracture surface of mix $\mathrm{H} 1$ tested in direct tension. Spacing of grids in photographs is $1 \mathrm{~mm} /$ grid.

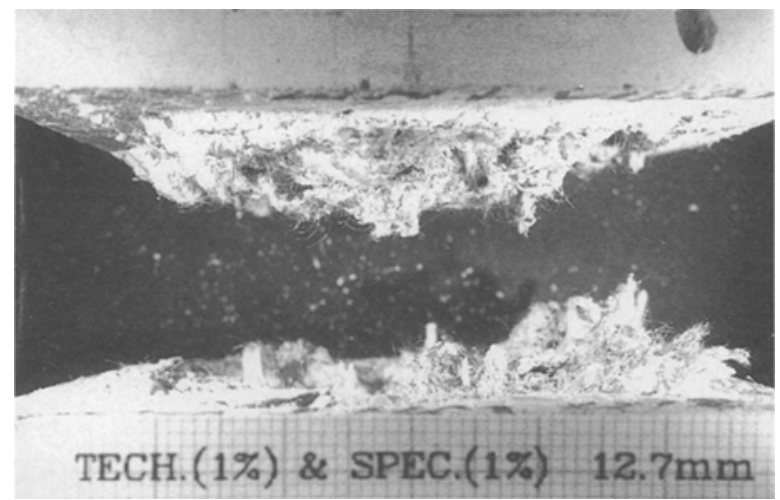

Figure 19 Photographs of fracture surface profiles of mix H1 tested in direct tension. Spacing of grids in photograph is $1 \mathrm{~mm} / \mathrm{grid}$.

mix T4 (Technora 1\% $12.7 \mathrm{~mm}$ ) and mix S1 (Spectra $9001 \% 12.7 \mathrm{~mm}$ ), indicating that the interference between fibres has lowered the efficiency of the fibre reinforcement. But nevertheless, a relatively high fracture energy and a relatively high post-cracking stress have been obtained, which confirms the advantages of hybriding.

\section{FRC with Herculon PP fibres}

Herculon PP fibres, also coated with a dispersionpromoting finish, appeared to distribute well in the matrix, as indicated by Fig. 20 for mix P1 containing $2 \% 5 \mathrm{~mm}$ fibres, and in Fig. 21 for mix P2 containing $2 \% 10 \mathrm{~mm}$ fibres. In these specimens, no apparent fibre bundles were found.

The fracture surface profiles of mixes P1 and P2 tested in direct tension are shown in Fig. 22. Apart from the fuzzy appearance due to fibres pulled out on the surface, the fracture surfaces of FRC with Herculon PP fibres (mixes P1 and P2) are very flat like that of plain mortar (Fig. 8), indicating that these lowmodulus polyolefin fibres do not provide significant resistance to planar crack growth in the matrix.

The Herculon PP fibres are undrawn filaments which exhibit an elastic-plastic behaviour in tension with a rupture strain of $366.6 \%$ [3]. During the direct tensile test, drawing of the Herculon PP fibres bridging the crack took place as the specimen crack opened. This process for mix P2 containing $2 \%$ $10 \mathrm{~mm}$ fibres is shown in Fig. 23. The majority of the fibres in mix $\mathrm{P} 2$ were pulled out, appearing in corrugated shapes (Fig. 24). Holes in the matrix left by the withdrawn fibres can be seen in the micrograph shown in Fig. 25. Ruptured fibres on the fractured surface, like that shown in Fig. 26, can also be seen, but they are very uncommon. The final specimen separation at which the stress dropped to zero was about $25 \mathrm{~mm}$ for $\operatorname{mix} \mathrm{P} 2\left(L_{\mathrm{f}}=10 \mathrm{~mm}\right)$. For mix P1 containing $2 \%$ $5 \mathrm{~mm}$ fibres, all the fibres bridging the crack in the tensile specimen were pulled out due to their short length, and the final crack separation for mix P1 was about $6 \mathrm{~mm}$. No matrix spalling was observed in the test of mixes $\mathrm{P} 1$ and $\mathrm{P} 2$.

The Herculon PP fibres were designed for use in non-woven materials and not specifically for use in FRC. They were included in this study to evaluate the hypothesis that undrawn fibres might contribute to concrete reinforcement. However, because of their low yielding stress, the fibres could not provide significant resistance to crack opening, and the FRC postcracking behaviour as indicated by the $\sigma-\delta$ curves for mixes P1 and P2 (Fig. 3) is unsatisfactory. Although
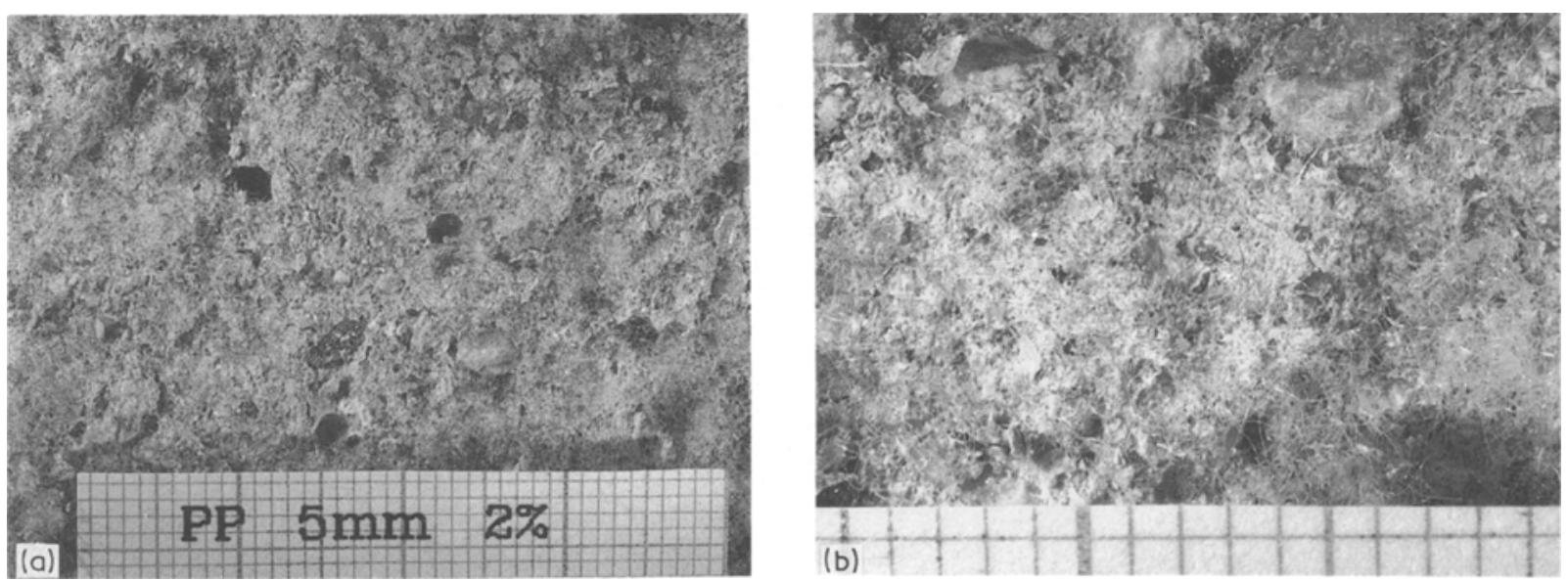

Figure 20 Photographs of fracture surface of mix P1 tested in direct tension. Spacing of grids in photographs is $1 \mathrm{~mm} / \mathrm{grid}$. 

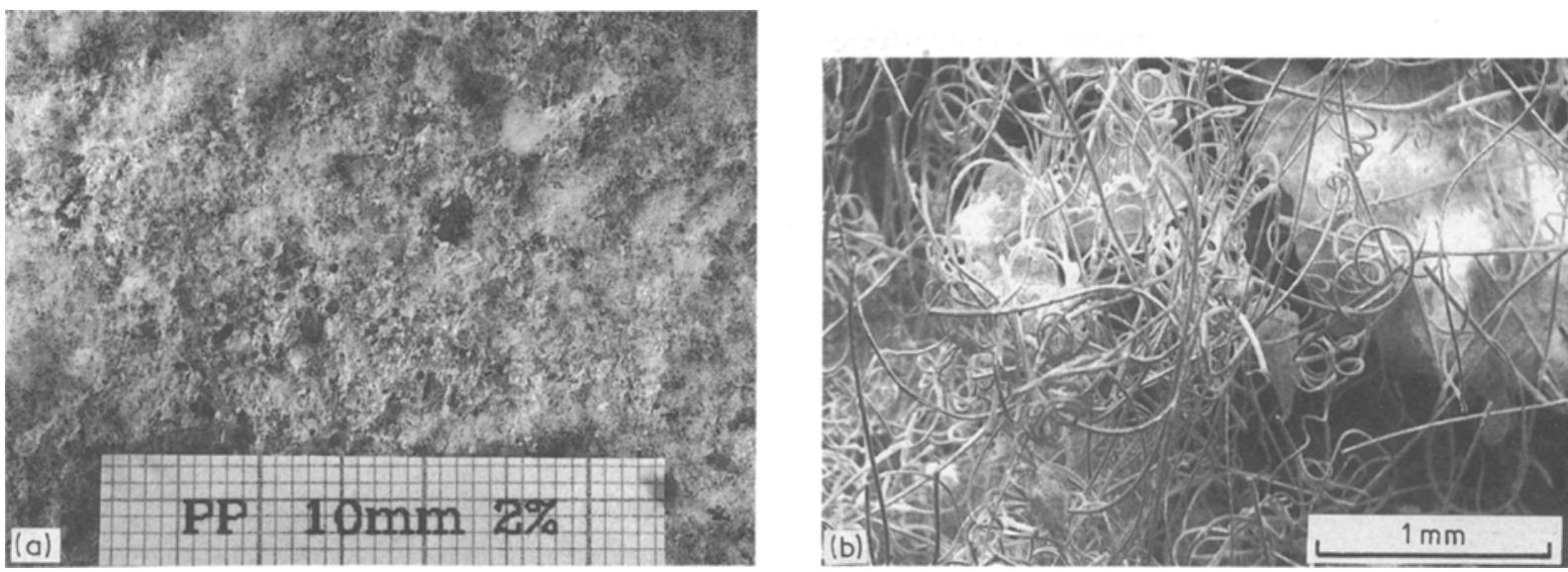

Figure 21 Photographs of fracture surface of mix P2 tested in direct tension. (a) Optical micrograph, (b) scanning electron micrograph. Spacing of grids in optical photograph is $1 \mathrm{~mm} /$ grid.
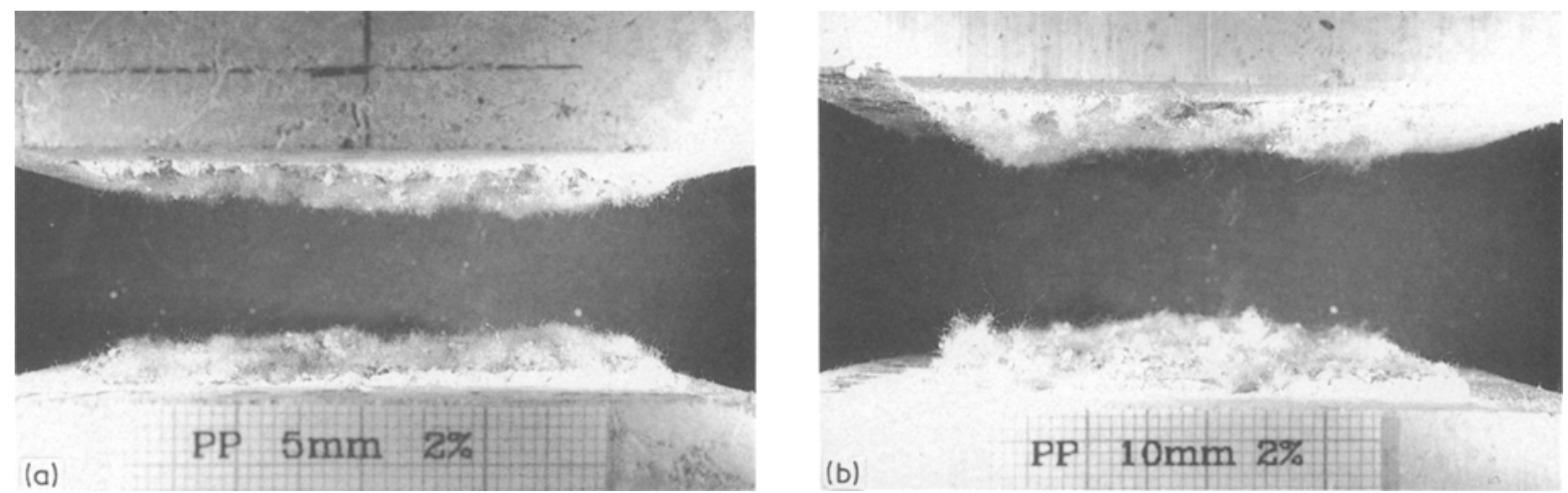

Figure 22 Photographs of specimen fracture surface profiles of mixes (a) P1 and (b) P2 tested in direct tension. Spacing of grids in photograph is $1 \mathrm{~mm} /$ grid.

the total energy absorption of mix P2 was impressive, the low post-cracking stresses of the Herculon PP FRC are undesirable, particularly in consideration of the serviceability requirement for concrete structures.

In view of their low cost and good dispersion property, these polypropylene fibres can still be very attractive for concrete reinforcement if the fibre strength and modulus are increased by modifying the drawing process of fibre production.

\section{Discussion}

The failure mechanisms of FRC with Spectra 900, aramid, and Herculon PP fibres have been discussed. For the fibre lengths and volume fractions used in this set of tests, the importance of these mechanisms in controlling the composite tensile behaviour can be summarized.

1. Fibre pull-out: important in Spectra and Herculon PP FRC; insignificant in aramid FRC.

2. Fibre rupture: present in aramid and Herculon $\operatorname{PP}\left(L_{\mathrm{f}}=10 \mathrm{~mm}\right) \mathrm{FRC}$, but not playing any significant role.

3. Matrix spalling: common in Spectra FRC with normal mortar matrix.

4. Matrix multiple cracking: observed in Spectra
FRC with normal mortar matrix, but only locally near the main fracture plane.

5. Bundle splitting: important in aramid FRC.

6. Bundle shearing: also important in aramid with long fibres $\left(L_{\mathrm{f}}=12.7 \mathrm{~mm}\right)$.

7. Fibre plastic deformation: important in Herculon FRC.

Based on these optical and SEM examinations, it is found that the uniformity of fibre distribution in the matrix was strongly dependent on fibre type and fibre volume fraction. The dependence on fibre type is presumably due to the differences in fibre finishes applied by the manufacturers to different types of fibres. The aramid fibres were found to distribute in the matrix poorly by forming large bundles or clumps, while Spectra 900 and Herculon fibres appeared to distribute uniformly in most cases. To achieve efficient reinforcement with aramid fibres, means must be provided to separate the fibres, by, for example, modifying the fibre surface finish or using mechanical devices. Based on a preliminary experiment, it appears that mechanical separation alone cannot provide satisfactory results, as the fibres tend to re-clump when dispersed in water after mechanical separation. Surface finish modification seems to be a necessity for even distribution of aramid fibres in cementitious matrix. 

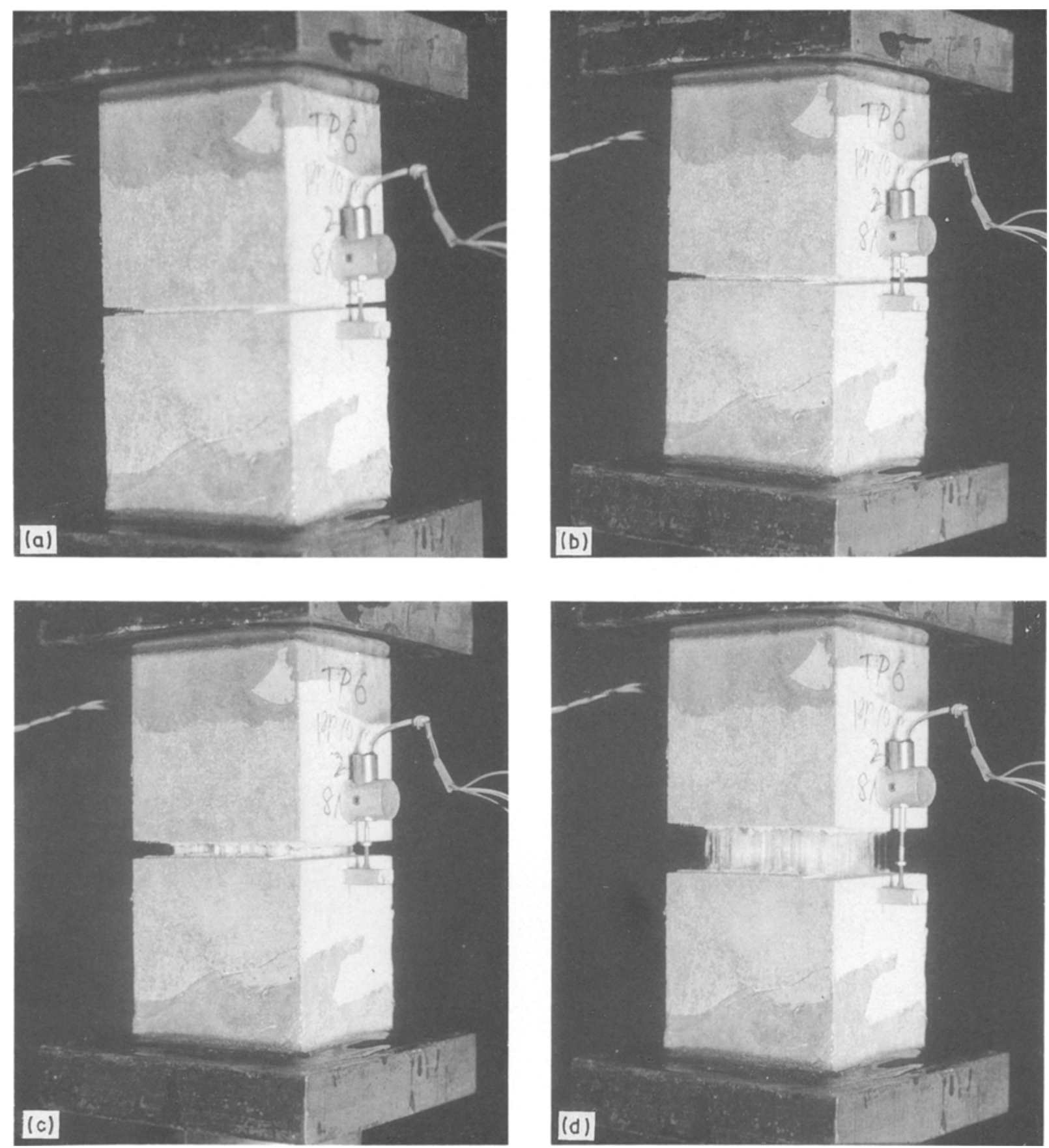

Figure 23 Failure sequence in direct tensile test of mix $\mathrm{P} 2$.

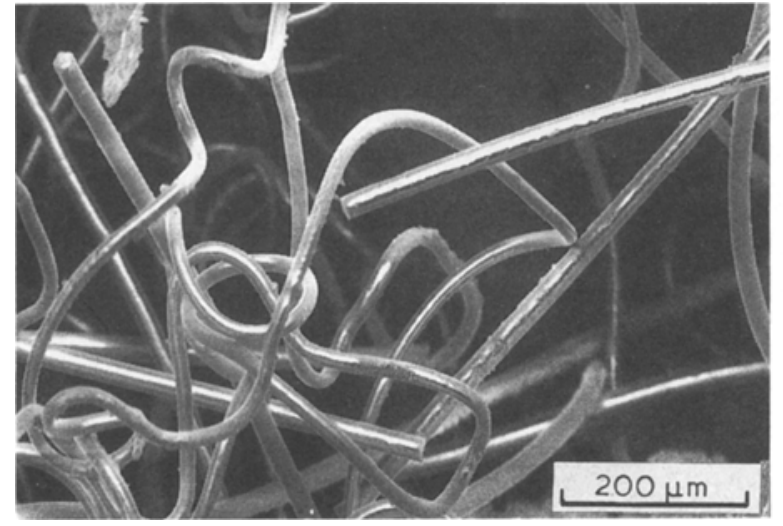

Figure 24 Appearance of fibres pulled out from the matrix in specimen of mix P2 tested in direct tension.

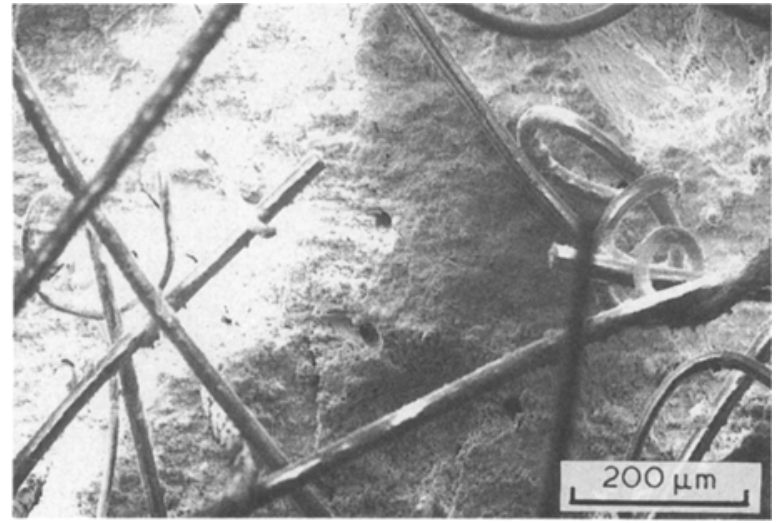

Figure 25 Scanning electron micrograph showing holes in matrix due to fibre pull-out in specimen of mix P2 tested in direct tension. 


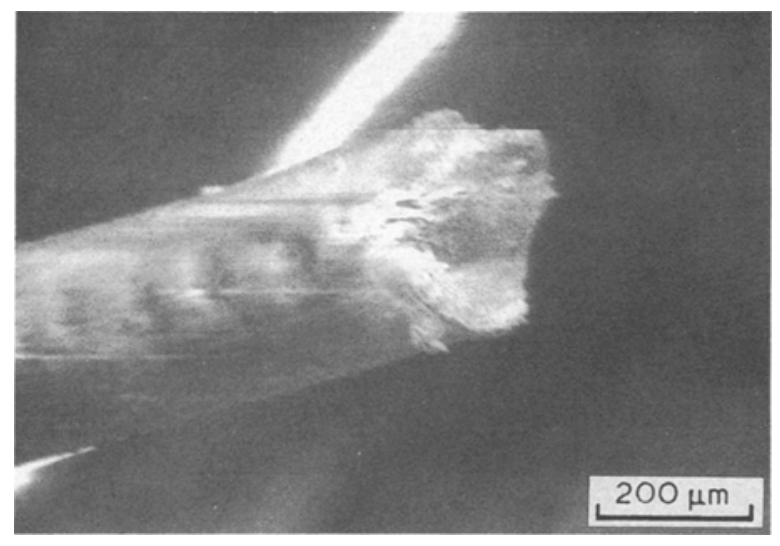

Figure 26 Scanning electron micrograph showing fibre ruptured end in mix $\mathbf{P} 2$.

It should be borne in mind that fibre reinforcement can significantly improve the ductility (toughness), but not the (compressive) strength of concrete. However, most designs of load-bearing concrete structures depend primarily on the strength of concrete. The main advantage of using FRC instead of plain concrete in structures is then the increased structural safety/ reliability against unexpected loads such as seismic ones, and the increased life expectancy. In order for FRC to be competitive with other materials, and for new types of FRC to be competitive with existing FRC, it is important that all the reinforcing fibres in FRC be effectively used.

In addition to uniform fibre dispersion, it has been suggested that for FRC with random fibre distributions, the following relation should be satisfied for efficient use of reinforcing fibres

$$
L_{\mathrm{f}} \approx L_{\mathrm{c}}=\frac{d_{\mathrm{f}} \sigma_{\mathrm{f}}^{\mathrm{u}}}{4 \tau}
$$

The fibre strength, $\sigma_{f}^{u}$, for a given fibre type is generally limited by the fibre production process (unless a lower fibre strength is required). It, along with other considerations, can be used as a guideline for fibretype selection. Similarly, the choice of fibre diameter, $d_{\mathrm{f}}$, could also be limited, particularly for some high performance fibres which are currently only available in a few fixed diameters. The length of fibres, $L_{\mathrm{f}}$, on the other hand, can be obtained easily over a wide range of values. However, to ensure good workability of fresh FRC, it is desirable for $L_{\mathrm{f}}$ to be less than about $30 \mathrm{~mm}$. As demonstrated, the fibre/matrix bond strength, $\tau$, can be changed by, for example, surface finish modification and/or mechanical crimping. Proper selections of $L_{\mathrm{f}}$ and $\tau$ are the important steps towards effective use of reinforcing fibres.
It has also been shown that sufficient matrix strength is required for the fibres to carry loads effectively. Application of high-strength concrete techno$\operatorname{logy}$ to FRC needs to be further explored. Another aspect worth further investigating is the use of hybrid fibre reinforcement.

\section{Conclusions}

Direct tensile tests were conducted on mortar specimens reinforced with various synthetic fibres including polyethylene, polypropylene, and aramid fibres. The tensile behaviour of FRC was measured and the failure mechanisms were identified. It was indicated that the unique tensile behaviour of each FRC can be directly related to the failure mechanisms involved in the test, and the failure mechanisms were closely related to the reinforcement parameters including fibre characteristics and the fibre/matrix interface properties.

In FRC containing well-dispersed fibres (polyethylene and polypropylene), fibre pull-out and stretching were the dominant mechanisms which led to relatively high energy absorption. In aramid FRC, on the other hand, most fibres were in bundle form. The fibre bundles caused the matrix crack to deflect out of plane and therefore the aramid FRC specimens showed improved tensile strength. However, the energy absorption of aramid FRC was relatively low due to the lack of fibre pull-out. For effective fibre reinforcement, it is suggested that the fibres should be uniformly distributed in the matrix and the fibre/matrix properties should be controlled such that most of the fibres bridging a matrix crack are pulled out.

\section{Acknowledgements}

The authors acknowledge the support of the Shimizu Construction Company Ltd, and the Program of System Engineering for Large Structures at the National Science Foundation.

\section{References}

1. A. Hiller bor G, Int. J. Cement Compos. 2 (1980) 177.

2. Y. WANG, V. C. LI and S. BACKER, J. Cement Concrete Compos. 12 (1990) 29.

3. Y. WANG, PhD thesis, Massachusetts Institute of Technology (June 1989).

4. Y. WANG, V. C. LI and S. BACKER, Amer. Concrete Inst Mater. J. 87 (1990) 461

5. Idem, Composites 20 (1989) 265

6. V. C. LI, Y. WANG and S. BACKER, J.Compos. 21 (1990) 132

Received 1 August 1989

and accepted 6 February 1990 